Gutenberg School of Management and Economics \& Research Unit "Interdisciplinary Public Policy" Discussion Paper Series

\title{
Monopoly Profit Maximization: \\ Success and Economic Principles
}

Korbinian von Blanckenburg, Milena Neubert

Mai 2014, updated November 2014

Discussion paper number 1406 
Contact details

Prof. Dr. K. v. Blanckenburg

Hochschule Ostwestfalen-Lippe

(University of Applied Sciences)

Liebigstraße 87

32657 Lemgo

Germany

korbinian@vonblanckenburg.de

Milena Neubert

Johannes Gutenberg-Universität Mainz

Jakob Welder-Weg 9

55128 Mainz

Germany

milena.neubert@uni-mainz.de

All discussion papers can be downloaded from http://wiwi.uni-mainz.de/DP 


\title{
Monopoly Profit Maximization: Success and Economic Principles
}

\author{
Korbinian von Blanckenburg ${ }^{a, *}$, Milena Neubert ${ }^{b, 1}$ \\ ${ }^{a}$ Hochschule Ostwestfalen-Lippe (University of Applied Sciences), Liebigstraße 87, 32657 Lemgo, Germany \\ ${ }^{\mathrm{b}}$ Johannes Gutenberg-University Mainz, Jakob Welder-Weg 9, 55128 Mainz, Germany
}

\begin{abstract}
This paper presents a classroom experiment on pricing strategies available to monopolists. Each student makes production decisions as a monopolist during the experiment, learning from his/her own experiences what it means to be a price searcher. Full information is provided on cost conditions, while the demand function remains unknown to the participants. Given a sufficient number of periods, students will in principle be able to maximise their profits by applying a simple trial and error strategy. However, one of the objectives of the experiment is to demonstrate to students that search strategies based on economic principles are more efficient.
\end{abstract}

Keywords: Classroom experiment, monopoly, trial and error, pricing strategy

JEL classification: A20, A23, L12

\footnotetext{
* Corresponding author; Tel.: +49-5261-7025536; E-mail address: korbinian@ vonblanckenburg.de

${ }^{1}$ Tel.: +49 613139 20885; E-mail address: milena.neubert@uni-mainz.de
} 


\section{Introduction}

It might be provocative to state that a typical student in an introductory course in economics would 'memorize a few facts, diagrams, and policy recommendations, and then ten years later [...] be as untutored in economics as the day he entered in class', (Stigler, 1963: 657). Surprisingly, few empirical studies have been published on this serious indictment of the sustainability and pedagogical effectiveness of economic teaching (Bach and Saunders, 1965, 1966; Saunders, 1980; Lynch, 1990; Allgood et al., 2004). The results of these studies, however, indeed consistently indicate minimal or even no lasting effects of introductory economic courses. Given these considerations, academic economists have continued to develop new teaching approaches over the past decades in order to improve the way in which economic principles can be taught. In this regard, a number of educators have highlighted the advantages of experimental learning in the classroom (Walker, 1987; French and Turner, 1989; DeYoung, 1993; Fels, 1993; Holt, 1999). Classroom experiments enable students to learn from their own experience, which may greatly improve their understanding of theoretical concepts (Parker, 1995). Accordingly, interest in using classroom experiments to teach economics is increasing (Dickie, 2006; Becker and Watts, 2007). Over the past three decades, teaching tools have been designed for several theoretical concepts, including price discovery mechanisms (French and Turner, 1989), Coasian bargaining (Leuthold, 1987), monopolies (Oxoby, 2001), voting paradoxes (Sulock, 1990), public goods (Brock, 1991), oligopolies (Nelson and Beil, 1995), and cartel behaviour (Bowes and Johnson, 2006). We add to this range by proposing a classroom experiment on monopoly profit maximization.

The classroom experiment described in this paper is based on a game developed by Nelson and Beil (1994), which demonstrates to undergraduate economic students what it is like to be a monopolist and enables them to investigate and consider pricing strategies first-hand.

The paper begins with theoretical background on the basic concept and learning goals. We explain the experimental design and the similarities, differences and enhancements with respect to Nelson and Beil (1994). To demonstrate the feasibility of concepts and to provide teachers with examples of results, we show the results of our classroom experiment, which was conducted in 2012 during a seminar at the University of Kassel, Germany. Afterwards, instructions for teachers are provided, demonstrating how the monopoly experiment may be used as a teaching tool in economic classes. In order to ensure that even novice experimenters will be able to apply the experimental procedures in their own classroom, sufficient detail is provided on experiment administration and on postexperimental discussion. The paper ends with a summary of the major insights. 


\section{The monopoly experiment}

\subsection{Experimental Design}

The monopoly experiment enables students to develop through first-hand experience a cognitive understanding of pricing strategies available to the monopolist. To achieve this, each student acts as a separate, independent monopolist during the experiment. Each participant is provided with a cost function, but the demand function remains unknown. In fact, locating the shape, slope and position of the demand function is one of the fundamental tasks during the experiment. The teaching tool is designed to proceed over multiple classroom periods. During each period, all students must submit a price at which they are willing to sell the product in the corresponding period, and a quantity that they will produce and offer for sale. However, there is no guarantee for the monopolist that all units can be sold. Assuming production in advance, under- as well as overproduction are possible. Consequently, only in the next period does the monopolist learn from the instructor, whether and how many of units were bought at the asking price. Given that each unit offered by the monopolist is produced, production costs will be incurred in any case - even if the goods remain unsold. Participants should aim to maximise their (cumulated) profits across all experiment periods.

Given a sufficient number of periods in which to search, most students will be able to find the profitmaximising combination of price and quantity by trial and error alone. However, it becomes evident through the course of the experiment that strategies based on economic theory are more efficient than trial and error. Furthermore, the experiment highlights that in the 'real world', demand functions are typically unknown, which hampers monopolists wishing to apply the strategies proposed by standard economic textbooks. Consequently, students discover personally that companies which are able to accurately assess the real market demand for their products, should benefit accordingly.

We use the basic framework of Nelson and Beil (1994) in our experiment, but provide some relevant and important enhancements. Their article and ours demonstrate to students the effectiveness of the economic principle of an optimal profit maximizing monopoly (MC=MR approach). Full information about the cost function is provided, participants know nothing about the constant demand function and the monopoly is a price searcher. In both articles, there is no guarantee that all units produced can be sold. Underproduction and overproduction are possible and unsold units cannot be carried over as inventory. Also similar to the experiment of Nelson and Beil (1994) is that bonus points are awarded for successful playing and based on profits.

However, there are notable differences to Nelson and Beil (1994): We assume that the product is not perishable and that units are divisible. We allow for fractional prices and quantities, and a cost function is given, but the demand curve is linear instead of a step function. This means that the exact profitmaximizing quantity can only be calculated by using the MC=MR approach. In Nelson and Beil 
(1994) the exact profit-maximizing quantity can be calculated accidently both by using the MC=MR approach and by trial and error, which is, however, not the best way. To make this clear, in our experiment the optimal quantity was $4.398,27567 \ldots$ a "trial and error" student may find 4.398 after 15-20 periods, but a "calculation" student who estimates demand and calculates the quantity with an $\mathrm{MR}=\mathrm{MC}$ approach will determine the quantity more precisely. Without fractional prices (as in Nelson and Beil) we would be unable to differentiate between such strategies. By allowing the participants to choose fractional prices and quantities (instead of whole numbers), our approach is closer to reality and able to give the students a more realistic picture of what markets look like and how they function. Only the right approach leads to the optimum, so that students who are able to determine the optimal level of production must have used the MR=MC-approach. Students who try to estimate the optimal production by minimizing marginal costs and/or merely by trial and error do not obtain the profitmaximum. The changed parameters thus differentiate between students who used the wrong approach and those who used the right one.

Secondly, our incentive structure contains three elements, i.e. an additional incentive for the applied strategy. Students who adopt the economic approach obtain extra points. Nelson and Beil (1994) also offer bonus points, but only based on accumulated profits. We extend the practice of awarding bonus points based on profits into the final period and to the applied strategy during the experiment. We believe this to be important, because students should have an incentive to find the best strategy and not to stumble upon a good result by trial and error only. There is some evidence that bonus points have a positive impact on learning success (e.g. Doyle/Carter, 1984). However, we can identify successful students particularly in the final phase of the experiment. Additionally, the student report on the applied strategy enables us to analyse their behaviour more precisely. Moreover, we present a method for collecting and using experimental data in an Excel framework and provide all the files needed by teachers free of charge. ${ }^{2}$

Furthermore we do not include a line-of-credit to cover losses, because this is not necessary.

\subsection{Sample experimental procedure}

In order to demonstrate the practical feasibility of the theoretical concept, in 2012, a sample experiment was conducted at the University of Kassel, Germany. Accordingly, 21 students of the seminar 'Basic Concepts of Competition Policy' were asked to take part in the monopoly experiment. Given that the seminar was designed for advanced Bachelor students in economics or related subjects, it can be assumed that all participants had already attended an introductory microeconomic courses before participating in this experiment. During the first classroom session, students were told that each

\footnotetext{
${ }^{2}$ Hyperlinks to our server can be provided upon request.
} 
of them would act as a monopolist, selling seven-league boots. Furthermore, they were provided with a cost function (TC), which was identical for all participants and read as follows:

$$
T C=350 Q-25 Q^{2}+Q^{3},
$$

where $\mathrm{Q}$ is the total quantity in thousands. The constant demand was given by the following linear and decreasing function, which was, however, not known to the students:

$$
p=\max \{496-35 Q, 0\}
$$

where $\mathrm{P}$ is the price in Euros.

We used a profit calculator which generates the subject's payoff when provided with his or her own selected quantity. Experiments that use a profit calculator are characterized by the fact that some investigators include a 'best-response option', which provides the quantity that maximizes the subject's payoff. The design of the experiment cannot fully prevent collusion between students, so that how exactly the information is given to them is particularly important. Requate and Waichman (2011) observe that less collusion occurs in the treatment with best-response options. In particular, there are only a few markets in this treatment that collude successfully. In our case, however, collusive behaviour was not observed at all. ${ }^{3}$ The experiment continued over a period of ten (weekly) classroom sessions. Each week, each participant submitted a bid for the quantity of seven-league boots that he was bringing to the market and the price he was asking on the university's student online platform. Before students had to submit their next bid one week later, they were individually informed how many of their units had been sold at their asking price. To increase the probability that participants would be able to figure out the optimum combination within the given time frame, students were allocated a constraint, indicating that the profit-maximising quantity of seven-league boots would lie between 1000 and 5000 pieces per week (so: $1<Q^{*}<5$ ) and the profit-maximising price would lie between $€ 50$ and $€ 350$. In the last period of the game, students were asked to provide feedback on the strategy which they had pursued during the experiment. Furthermore, participants were able to evaluate the classroom experiment.

To motivate students to take part in the experiment and to ensure that they provide the appropriate level of effort, participants were provided with bonus grade points for being successful in the experiment, which were based upon the following criteria: level of cumulative profits over all ten

\footnotetext{
${ }^{3}$ In fact, collusion in a cartel situation was not possible in our experiment, as each student operated in a separate market. However, we were using identical demand functions for all students. Through exchanging their experiences during the course of the experiment, students could therefore have discovered that they were all facing the same demand conditions and collude. We used identical demand functions for the sake of simplicity in our experiment. Nonetheless, our design does also allows for using differing functions. Teachers who wish to implement this in their own classroom should be aware that using multiple demand functions requires additional effort in the preparation and analysis of results.
} 
periods (40\%), level of profit in the last period (40\%), and strategy applied during the experiment ${ }^{4}$ (20\%). A maximum of up to ten bonus points (ca. $20 \%$ of the final grade) could be earned by the students, which were added to the result of the written exam at the end of the seminar.

\subsection{Theoretical solution}

One of the first things which undergraduate students learn in microeconomics classes is that, having no rivals by definition, the monopolist has a unique position in the market. If he decides to raise the price he does not have to worry about potential competitors (Boyes and Melvin, 2012: 200-209). However, this does not imply that the monopolist is able to charge any price he wants for his goods at least not if he aims at profit maximisation. Rather, to maximise profits, the monopolist needs to define his costs, analyse the market demand and decide accordingly. In the classroom, this is typically illustrated graphically by establishing the profit-maximising quantity at the intersection of the marginal cost (MC) and marginal revenue (MR) curves, and finally determining the price from the demand function (Boyes and Melvin, 2012: 200-209).

However, as in real-world situations, the demand function is unknown to the students participating in the monopoly experiment. Consequently, in order to maximise profits, participants basically have two options. The one is to approach the profit-maximising $\mathrm{P}$ and $\mathrm{Q}$ by trial and error, exploring various combinations of total revenue and total costs until they have established the combination that constitutes a global maximum. The other option is to access their knowledge of basic microeconomic principles to locate the demand function, and apply the MC=MR approach. In fact, students who have not attended microeconomic classes or do not know how to operationalize it, are likely to use a trial and error strategy (Nelson and Beil, 1994: 288).

Figures 1 and 2 demonstrate how students can estimate the profit-maximising combination using economic principles. Applying economic principles would theoretically enable a student to find the profit-maximising combination in week three of the classroom experiment. Students have complete information about the cost curve. However, to identify the profit-maximising combination by applying marginal principles they first need to estimate the prevailing demand function. To achieve this,

\footnotetext{
${ }^{4}$ We awarded bonus grade points for the "strategy applied", firstly by considering students' self-reports and secondly by aligning observed behavior with these reports. As discussed in Section 2.1, allowing for fractional prices and quantities enabled us to differentiate between student strategies with relative certainty. Students who had calculated the optimum by using economic principles and presented a convincing process of calculation in their reports obtained the best score. Students, who used trial and error, but showed an awareness in their reports that they should have used economic principles, explain why this is the case, as well as how they should have proceeded to calculate the optimum, obtained the second-best score. Participants who simply stated that they had used trial and error were awarded the lowest score. Students who did not explain clearly how they approached the experiment or whose explanations were not in line with their actual behavior during the experiment did not receive any bonus grade points in this category.
} 
participants must choose combinations of price and quantity, which lead to overproduction in the first two weeks, bringing them back to the band defining the demand frontier after the instructor has informed them how many of the units offered had been sold at their asking price.

Consider the following example depicted in Figure 1. Student A submits a price of $p=€ 350$ and a quantity of $\mathrm{Q}=5$ in Period 1 , which - given the restricted ranges of prices and quantity - is likely to lead to overproduction. At the beginning of the second period the student learns from the instructor that he was not able to sell all of his/her units offered at a price of $p=€ 350$, but only sold $Q=4.17143$ units. The student now knows one combination of price and quantity which lies on the demand function. In the second period, the student will again try to offer a quantity which leads to overproduction. At the end of the second period, students have two combinations of price and quantity with which they may calculate the linear demand function. ${ }^{5}$

\begin{tabular}{|c|c|c|c|}
\hline Student A & Q (offered) & $P($ offered $)$ & Q (sold) \\
\hline Period 1 & 5 & 350 & $Q=\frac{496-350}{35}=4.17143$ \\
\hline Period 2 & 4.7 & 347 & $Q=\frac{496-347}{35}=4.25714$ \\
\hline \multicolumn{4}{|c|}{ General shape of linear demand curve: $P(Q)=-m Q+b$} \\
\hline (I) & \multicolumn{2}{|c|}{$350=-m * 4.17143+b$} & \\
\hline (II) & \multicolumn{2}{|c|}{$347=-m * 4.25714+b$} & \\
\hline \multicolumn{3}{|c|}{$3=-0.08571 m$} & \\
\hline \multicolumn{3}{|c|}{$\Leftrightarrow m \approx-35$} & \\
\hline \multicolumn{4}{|l|}{ in $(I):$} \\
\hline \multicolumn{4}{|c|}{$350=-35 * 4.17143+b$} \\
\hline \multicolumn{4}{|c|}{$\Leftrightarrow b \approx 496$} \\
\hline \multicolumn{4}{|c|}{$\Leftrightarrow$ Demand Function: $p(Q)=496-35 Q$} \\
\hline
\end{tabular}

Figure 1: Exemplary estimation of demand function

\footnotetext{
${ }^{5}$ Note: Students should be made aware that overproduction may lead to net losses in the experiment, as revenue only arises from units actually sold, while - assuming production in advance - costs are incurred for any unit offered!
} 
Having calculated the prevailing demand function, students may now determine the profit maximum by equating MC and MR.

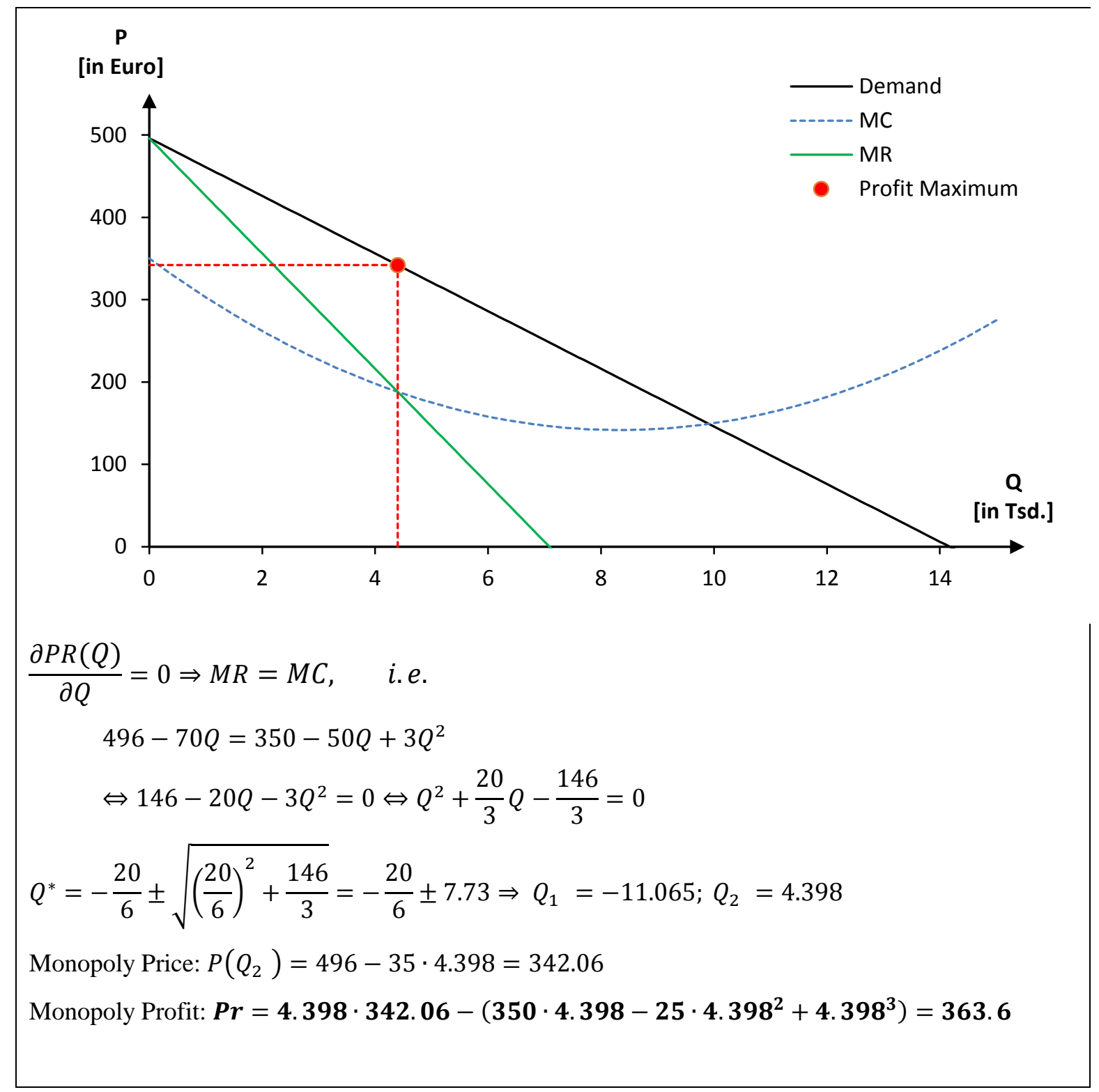

Figure 2: Graphical and analytical determination of profit-maximising price-quantity combination

\subsection{Results from sample experiment}

Figure 2 shows students' single-period profits over the course of the ten experimental periods. The figure reveals that while participants were theoretically able to find the profit-maximising combination of price and quantity (we therefore show the development of profits and not of quantities or prices in particular) within three weeks, none of the students taking part in the sample classroom experiment was able to actually reach the optimum by then. 


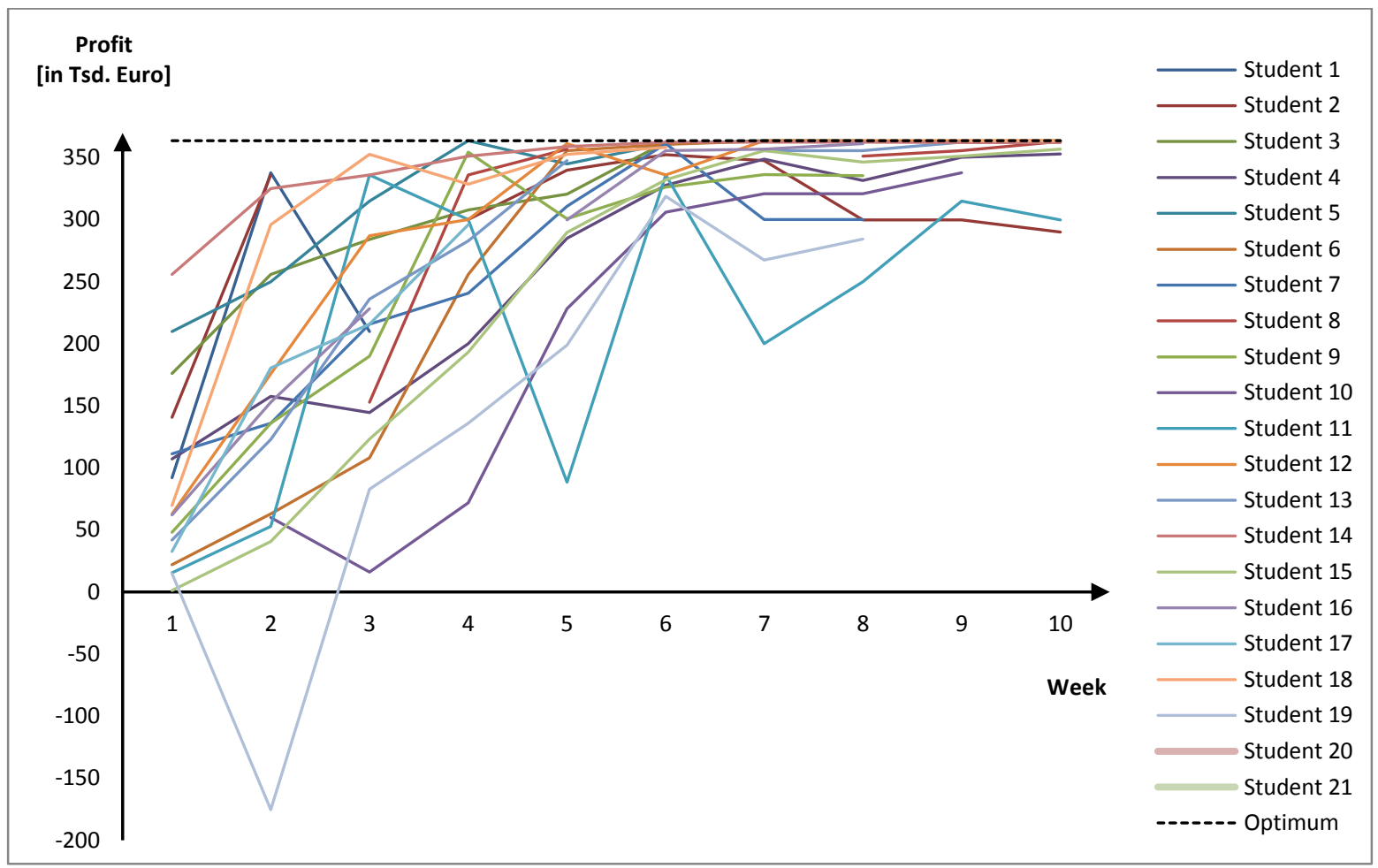

Figure 3: Evolution of single period profits per student over time

Figure 3 demonstrates the price-quantity combinations which were sold on the experimental market over the course of the ten game periods, adjusted for the prevailing demand, marginal costs, and marginal revenue curves:

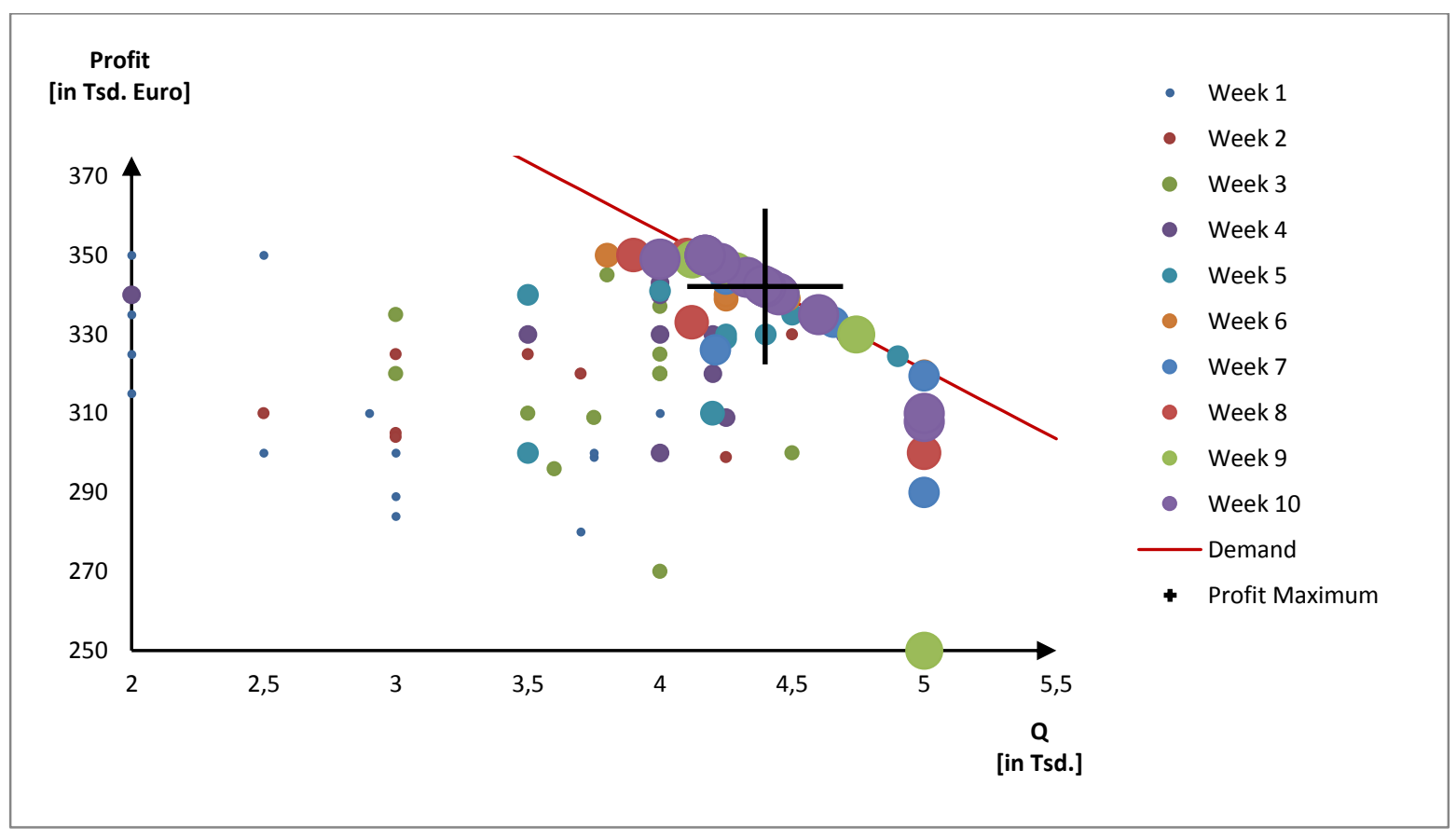

Figure 4: Quantities sold and optimum 
By the end of the experiment in week ten, only one student (Student 5) had managed to achieve the calculated profit-maximum of $€ 363.616$. Six students were very close to the optimum in the last period $^{6}$, three were fairly close the optimum ${ }^{7}$, while the remaining eleven were still searching when the game ended. ${ }^{8}$

A detailed analysis of the results indicates that Student 5 was presumably the only one applying economic principles to reach the optimum. ${ }^{9}$ All other students seem to have used trial and error - or at least were not able to calculate the correct profit-maximising combination of price and quantity. However, when asked about their strategy, nearly all students claimed that they had applied economic principles. Since, in several cases, this is not reflected in the data it seems likely that - besides those who were not able to properly calculate the optimum - several participants were not willing to admit that only after the game, had they realised that calculating the optimum from marginal principles would have been the theoretically optimal procedure.

Interestingly, while Student 5 managed to be the first to reach the optimum in week four, it took his fellow students significantly more time to (almost) do so. Only from week seven onwards, did more students manage to get close to the optimum. While some who were obviously applying a trial and error strategy, proceeded very systematically in trying new price-quantity combinations and thus raising their profits slightly each week, other acted less methodically. In fact, applying trial and error appeared to be a promising strategy for some participants. Besides leading some of these students very close to the calculated single-period profit-maximum, in terms of cumulative profits, two of them were even more successful than Student 5 who had applied marginal principles.

\footnotetext{
${ }^{6}$ Less than $1 €$ from profit-maximum.

${ }^{7}$ Between $1 €$ and $2 €$ from profit-maximum.

${ }^{8}$ It might seem rather unusual to promote a classroom experiment in which more than half of the students were still searching for the solution at the end of the game. On the other hand, all but one student increased their profits over the course of the experiment, which indicates good learning effects. The fact that 11 of 20 still did not manage to get closer to the optimum might also be attributed to the duration of our experiment. In the original game developed by Nelson and Beil (1994), sixteen periods were played, whereas "the first student found the profit-maximizing P and Q after about ten periods" (Nelson and Beil, 1994: 288). In fact, this might also be the reason why no student applying trial and error had reached the calculative profit maximum by the time the game ended. Due to the fact that we use fractional prices and quantities it is likely to take students longer to find the optimal combination by trial and error. Teachers using this design should therefore carefully consider how many periods to play. Even so, it should be mentioned that it is surprising that advanced Bachelor students who had all attended microeconomic courses before, are obviously not very proficient in the microeconomic basics which would have enabled them to use economic principles to calculate the optimum. This observation underlines the assumption made in the introduction about the need for new teaching approaches - like this experiment - which should contribute to student understanding of basic theoretical concepts.

${ }^{9}$ This conclusion was drawn as he was the only student who chose the correct profit-maximising price-quantity combination during the course of the experiment. Because we allowed for fractional prices and quantities, it was unlikely that participants would find this point without a prior calculation of profit-maximising values.
} 
Figure 4 displays the profits earned per week and student. We identified four different patterns of behaviour pursued during the experiment and allocated student performance accordingly. ${ }^{10}$ While only Student 5 successfully applied the MC=MR approach, several proved to be systematic and fairly successful trial and error strategists. Furthermore, the performance of two students indicates a significant learning process during the experiment. However, five students acted completely unsystematically.

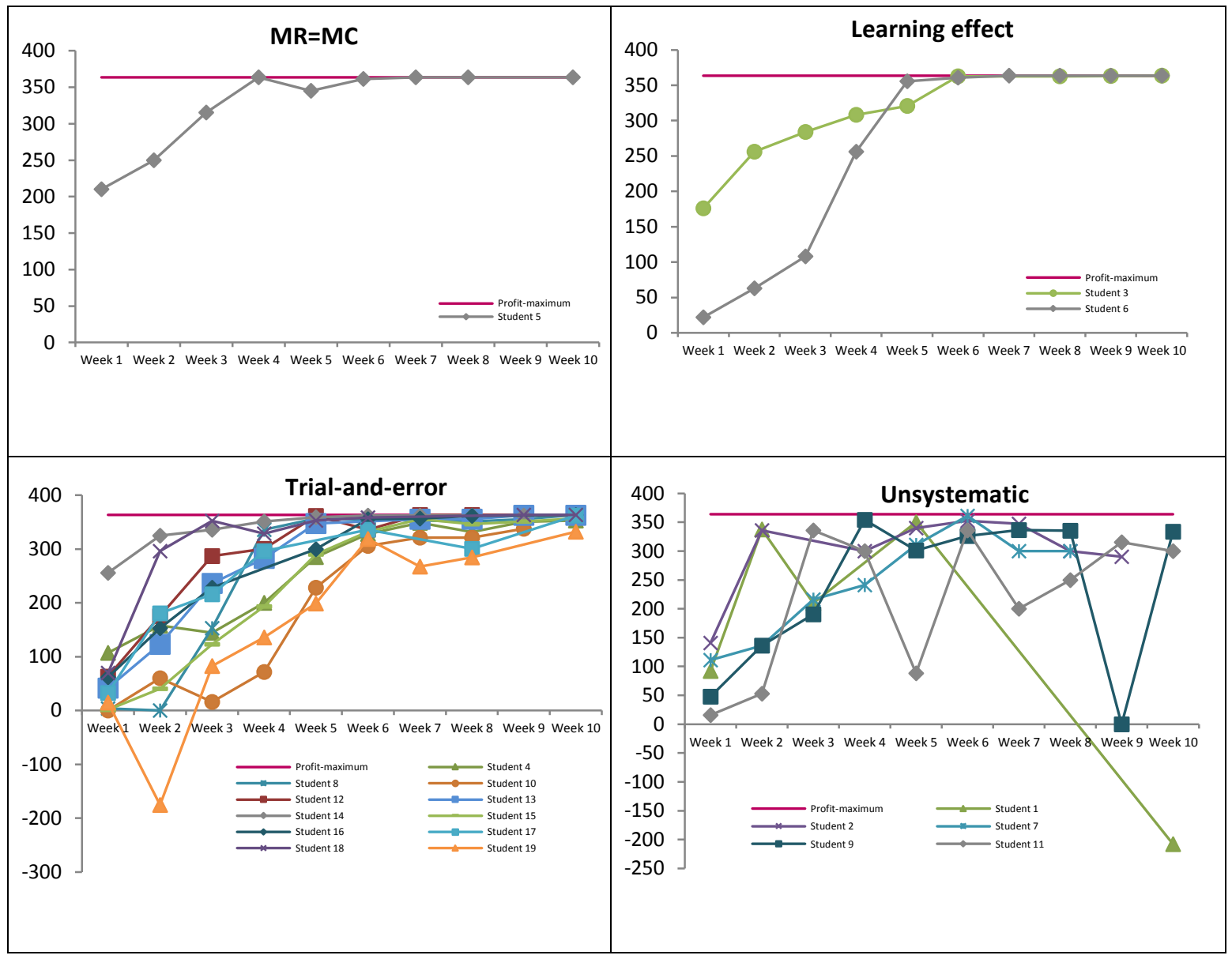

Figure 5: Patterns of behaviour

\footnotetext{
${ }^{10}$ Students were classified mainly on the basis of their suggested price-quantity combinations, which were analysed in combination with their self-reported strategies. As already mentioned, in many cases the selfreporting of strategies was not completely consistent with the results. We still found the self-reporting of strategies by students to be very useful, as aligning their (often quite detailed) explanations with observed behaviour enabled us to at least partly evaluate the true motives behind their behaviour. Nonetheless, teachers are well advised to interpret self-reports with a degree of scepticism and carefully align them with students' real behaviour in the game. See Section 3.1 for a discussion of why we think that self-reports in our experiment often do not correspond with the results. Due to the high number of missing values, Students 21 and 22 were excluded from the classification in Figure 4.
} 
As already noted, Student 5 applied basic economic principles to maximise his profits. In weeks one and three he managed to submit price-quantity combinations which led to overproduction. This provided him with valuable information leading him back to the band defining the demand frontier. By calculating the prevailing demand function he was able to reach the profit-maximum in week four by applying the MC=MR approach. However, he obviously had doubts about his methodology which he also admitted when explaining his strategy at the end of the experiment - trying to figure out whether profits could be increased by small changes in price and quantity in weeks five and six. Once he had realised that this was not possible, he chose the profit-maximising combination of price and quantity until the last period.

Analysing the results in detail, it appears that two students had been through a significant learning process during the experiment. ${ }^{11}$ Both Student 3 and Student 6 somehow misunderstood at the beginning of the experiment, and needed a few periods to learn how profits could effectively be increased. Recapitulating from his feedback, Student 6 claimed to have planned to estimate the demand function from the bottom. This in fact reveals him as not having understood the underlying principles sufficiently. As already mentioned in Nelson and Beil (1994: 289), the value of information on underproduction is low, simply defining 'a point in the interior space below the demand function'. Only after week four did he realise that his strategy was not effective. In rounds five and six, he therefore offered quantities which could not possibly be sold completely, providing him with information for calculating the prevailing demand function. However, while from week seven onwards he managed to get very close to the profit-maximum, a marginal increase in profits would have still been possible. This indicates that either the student was not able to calculate the correct values or that getting so close to the optimum must be attributed to a successful trial. On the other hand, Student 3 admitted that he had tried mark-up pricing in the first rounds of the game. Only after some weeks did he realise that profits could be increased far more when demand was taken into account.

Students who applied a systematic trial and error strategy typically started with a more or less successful guess in the first week of the experiment. Subsequently, they continued to increase their profits by trying new price-quantity combinations each week. While several students applied a very

\footnotetext{
${ }^{11}$ Given that both of these students managed to systematically improve their profits over the course of the experiment, they could also have been classified as systematic 'trial and error strategists'. Still, their selfreported strategy explanations reveal that these two students had been mistaken about an appropriate course of action at the beginning of the experiment, and needed some periods to discover a more effective strategy. In order to make students aware of different motives underlying participants' behaviour and to demonstrate the learning effects which can be achieved with this experimental design, it might therefore be useful for teachers to separate these two categories, if results enable this.
} 
systematic search process which enabled them to get very close to the profit-maximum in the last rounds of the game ${ }^{12}$, others who applied this pattern of behaviour were still searching in the last week. Five students were revealed as acting completely unsystematically during the game, which can also be read from the graph. They did not seem to follow a specific strategy, but rather to guess arbitrary combinations of price and quantity.

The results broadly illustrate the underlying theory; the monopolist is not able to sell all the units he wants to produce at any price. Rather, demand is a force to be reckoned with if the aim is to maximise profits. Given a sufficient number of periods, search strategies based on trial and error enable the monopolist to get very close to the optimum. However, it becomes apparent that applying economic principles is more efficient, enabling the monopolist to reach the profit-maximum after only a few periods. In fact, the experimental results demonstrate impressively that monopolists who are able to estimate the market demand correctly, have a profit-making advantage. In real-world situations, however, monopolists may still have good reasons to prefer the trial and error approach, as it is costly and hazardous to experiment with large price changes (Nelson and Beil, 1994: 294).

\section{Instructions for teachers}

\subsection{Procedures, record keeping and incentives}

In principle, the monopoly experiment is directed at undergraduate students from all disciplines who may or may not have attended a course in microeconomics. That is, understanding the application of the $\mathrm{MC}=\mathrm{MR}$ approach is not a prerequisite for participating successfully in the game (Nelson and Beil, 1994, 288). In order to use the experiment in the classroom, teachers first need to define both a cost as well as a demand function for the market and to estimate the profit-maximising combination of price and quantity. Choosing a constant, linear, and decreasing demand function is the simplest way to proceed. However, teachers may also deviate from this approach. As demonstrated in the sample experiment, identical cost and demand functions for all participants can be used, which simplifies the analysis of results. However, students will eventually discover over the course of the experiment that they all face the same demand conditions. Nonetheless, this is not likely to become apparent until late in the game (Nelson and Beil, 1994: 289). Furthermore, teachers may restrict the range of quantities and prices which can be offered. It is not necessary to have such restrictions, but this approach may accelerate the experimental procedure. It is advisable to come up with a specific product which students offer on the experimental market. Although it is not necessary to choose seven-

\footnotetext{
${ }^{12}$ Student 14 serves as a perfect model for the observation that trial and error strategies might be a promising means of achieving high profits, as this student displayed the highest cumulative profit of all participants at the end of the experiment.
} 
league boots specifically, as in the sample experiment, trading a specific good will probably enable students to relate more effectively to the situation of the supplier.

In the first session, teachers can hand out written instructions to the students or present the underlying assumptions by other means. ${ }^{13}$ To ensure that all students really understand these assumptions, participants should feel free to discuss any questions with their teacher before the experiment begins. This may in principle affect the results, depending on the nonverbal cues, but Bischoff and Frank (2011) found almost no evidence that an instructor can - even inadvertently - induce certain behavioural patterns among the students.

Record keeping is most efficient when students submit their 'Price Asked and Quantity Offered' combinations and receive their 'Quantity Sold and Profit' feedback via an appropriate online system. However, this procedure could also be substituted by a 'paper-and-pen method'. In any case, teachers should make sure that students receive their feedback individually to prevent them from realising that all students have identical demand conditions, as well as for privacy protection. The classroom experiment is designed to be conducted over several classroom sessions. While participants would theoretically be able to find the profit-maximising combination within three weeks, several rounds are necessary to demonstrate that a trial and error approach can also yield an optimum - especially when allowing for fractional prices and quantities. As shown in the sample results, to achieve learning effects for the majority of students, multiple periods need to be played.

After the last round of the experiment, teachers should ask participants to specify in a short questionnaire the strategy they had used during the experiment. The process may explain student behaviour during the game. Besides the strategy, other questions may be added, depending on the preferences and objectives of the instructor. ${ }^{14}$ In experimental research, questionnaires are commonly used after the games have been played. The reason is to prevent introducing an experimenter bias, with some participants reacting to the intended goal of an experiment (Rosenthal, 1976; Zizzo, 2010). Since minimizing such bias is one of the fundamental objectives of experiments, and since this would probably have unintended learning effects, this standard sequence was also adhered to during the sample experiment. However, this procedure may still introduce a post-experimental bias if subjects adjust their responses to the questionnaire, depending on how they acted in the preceding experiment.

\footnotetext{
${ }^{13}$ Sample instructions can be provided upon request. Teachers are welcome to complete and duplicate these instructions for own use.

14 The questionnaire used during the experiment can be provided upon request. Original documents were in German and have been translated for the purposes of this paper. Note: Besides using a questionnaire to let students evaluate the experiment, academic teachers may use the results of the classroom experiment to conduct their own research on underlying correlations. For example, control questions on basic microeconomic principles might expose correlations between a fundamental knowledge of economics and success in the monopoly experiment. Furthermore, by using demographic variables, researchers may test for a gender effect in applying a trial and error strategy as opposed to economic principles as a means of approaching the profitmaximum.
} 
As demonstrated, by comparing feedback on the applied strategies with actual behaviour in the sample experiment, it can be assumed that some students in fact succumbed to this post-experimental bias, concealing their actual strategy to please the instructor.

To motivate students to take part in the experiment and to make sufficient efforts to maximise monopolistic profits, teachers are advised to formulate positive incentives for participants. One possibility is to convert profits from the game into bonus grade points for the course. During the sample classroom experiment students were able to gain bonus grade points on the basis of three criteria, namely accumulated profit after the last experimental period, achieved single-period profit in the last week, and strategy applied during the experiment. However, including feedback on the strategy in the conversion to bonus grade points might have had an unfavourable effect in the sample experiment through inducing post-experimental bias. Some students were probably afraid of failing to achieve bonus grade points, if they admitted having applied a trial and error strategy instead of using marginal principles to calculate the profit-maximum. Consequently, several students tried to invent rational explanations for their (irrational) behaviour after they had realised that applying economic principles would have been the most favourable strategy. Given the underlying assumptions of the classroom experiment, overproduction may in fact lead to net losses, if gross revenues do not exceed costs (Nelson and Beil, 1994: 288). In view of the potential for incurring losses, teachers who convert earnings into bonus grade points are advised to make sure that no student could be disadvantaged by taking part in the classroom experiment, and thus always provide students with a positive incentive to play the game. As demonstrated by Nelson and Beil (1994: 289), teachers may for example set up a line-of-credit to cover possible losses.

About one hour is needed to give the instructions for the experiment. During the experiment teachers may calculate the results after each round and make them available to the students. Using our Excel sheet this can be done quite quickly (five to ten minutes after each round). In the end, two more hours are needed to present and discuss the results, the best strategy and do the evaluation. Finally, teachers may need ten to twenty minutes to analyse the evaluation and determine the bonus points.

\subsection{Post-experimental discussion and possible extensions}

To maximise learning effects teachers should in any case conduct a post-experimental discussion after the experiment. By producing different forms of graphs, teachers can effectively depict the results to the students. As done in the sample results, different patterns of behaviour may be demonstrated to the students by showing the results of individual participants over time. Teachers should discuss with their students the fact that two different strategies may lead to the profit-maximum, ideally presenting the results of two students, each of which used one of the two alternative approaches. 
Furthermore, students should be made aware of how the results of the classroom experiment illustrate the underlying theory. In this regard teachers may also discuss theoretical aspects, to refresh the students' knowledge of basic microeconomic principles.

Teachers can use the post-experimental discussion to point out that some of the real-world conditions did not operate in the experiment. Especially the static nature of the model needs to be taken into consideration. That is demand and cost functions are held constant over the course of the experiment, indicating that production decisions at no time affect demand and cost conditions. However, in the real world, a more dynamic environment needs to be assumed, which also has implications for the optimal pricing strategy of the monopolist (Dolan and Abel, 1981).

To adapt the classroom experiment to the specific topic of a course or to apply the classroom experiment in more advanced classes, several types of extension are possible. As proposed by Nelson and Beil (1994: 294), an interesting extension might be to compare the results of the monopoly experiment with those of a competitive market experiment. For this purpose, teachers may tell their students subsequently to the monopoly experiment that the existing (regional) monopolies will now be centralized to form a competitive market. Students may then continue submitting their pricequantity combinations. However, they will soon become aware that they will not be able to achieve the same high prices as before and that profits will decrease. By analysing the differences between from the monopoly and the competition experiment teachers may be able to depict the welfare effects of monopolies to their students. In order to extend the existing experiment appropriately, instructors need to adapt the market demand curve to the new assumptions. Specifically, individual demand curves need to be vertically aggregated to a common market demand curve. Cost functions may remain the same in the extended experiment.

A second possible extension is to demonstrate to students the impact of price agreements on market prices and profits. For this purpose teachers may ask some of the participants to form a group and develop a collective strategy. Theoretically, this cartel group should be able to influence the market and generate cartel profits. The cartel case may then be compared to those from the monopoly experiment and/or the competition experiment. As demonstrated by Nelson and Beil (1995), interesting results may also be obtained by forming oligopolies in the classroom.

Teachers may also be interested in measuring students' improvements over the course of the experiment. To achieve this they may use a set of questions testing basic microeconomic knowledge before and after the classroom experiment and compare the results.

\section{Conclusion}

For most teachers, conducting an experiment during class constitutes a dramatic departure from conventional introductory economic classes. In fact, this can be considered both as an argument in favour, as well as against using experiments in the classroom. Through providing a welcome change 
from typical ivory tower teaching, students are likely to enjoy and remember experiments and the associated classroom sessions (Parker, 1995: 4). However, the converse of the same argument is that preparing and evaluating classroom experiments is likely to require more effort from the instructor than would be the case for normal teaching. Even so, educators have long recognized that classroom experiments may deeply impact on student understanding of theoretical concepts. Instead of the rather passive role which they typically play in the classroom they are actively involved in the learning process (Durham, McKinnon, and Schulmann, 2007; Dickie, 2006). Many students are likely to have had only limited experience making economic decisions, especially supply-side - and this can be amended by simple means, through classroom experiments (Parker, 1995: 4).

The monopoly experiment described in this paper has been designed to demonstrate to undergraduate students pricing strategies available to the monopolist. In fact, feedback provided by the students who took part in the sample experiment indicated that learning objectives could be achieved effectively with the help of the teaching tool. Students acknowledged that after the game they had a greater understanding of the theoretical microeconomic principles of monopolies. Several participants furthermore indicated that they now realised that, even being aware of the underlying economic principles, monopolists in the real world may not be able to apply them so simply, as they do not have full information about demand conditions. The experiment is also designed to demonstrate the constraints of economic models. In real-world situations, the monopolist is typically unaware of his demand function. By literally being placed in the economic environment in question, students experience first-hand how sensitively pricing strategies of the monopolist react to information on consumer demand (Spulber, 1991: 2). In short, uncertainty affects economic decisions. Looking beyond the world of theoretical models and assumptions and at the real world in which one is often not able to predict (firm) behaviour in a realistic manner, ${ }^{15}$ the monopoly experiment not only enhances student understanding of theoretical microeconomic concepts, but also encourages them to critically challenge what they experience.

This paper incorporates some significant changes in comparison to Nelson and Beil (1994) so that the new article fulfils the predefined aims of the experiments to a greater extent. This is achieved by (i) effectively testing and teaching knowledge without alienating the students, (ii) reducing the time necessary to conduct the teaching-method in class, (iii) motivating students to engage seriously in the experiment and search for ways to find the optimum, (iv) providing detailed aspects of studentbehaviour and (v) allowing researchers as well as instructors to draw more precise and reliable conclusions from the data.

\footnotetext{
${ }^{15}$ Attempts to empirically and analytically analyse monopoly behaviour under uncertainty have, amongst others, been made by Chong and Cheng (1975), Meyer (1975), Appelbaum and Lim (1982), and Nocke and Peitz (2003).
} 


\section{References}

Allgood, S., Bosshardt, W., van der Klaauw, W., Watts, M., 2004. What Students Remember and Say about College Economics Years Later. American Economic Review, 94 (2), 259-265.

Appelbaum, E. and Lim, C., 1982. Monopoly versus Competition under Uncertainty. The Canadian Journal of Economics, 15 (2), 355-63.

Bach, G.L. and Saunders, P., 1965. Economic Education: Aspirations and Achievements. The American Economic Review, 55 (3), 329-56.

Bach, G.L. and Saunders, P., 1966. Lasting Effects of Economic Courses at Different Types of Institutions. The American Economic Review, 56 (3), 505-11.

Becker, W.E. and Watts, M., 2007. Teaching Tools: Teaching Methods in Undergraduate Economics. Economic Inquiry, 33 (4), 692-700.

Bischoff, I. and Frank, B., 2011. Good news for experimenters: Subjects are hard to influence by instructors' cues. Economics Bulletin, 31 (4), 3221-25.

Bowes, D.R. and Johnson, J., 2006. A Classroom Experiment in Cartel Behavior. [pdf] Available at: http://papers.ssrn.com/sol3/papers.cfm?abstract_id=942858 [Accessed February 10, 2014].

Boyes, W. and Melvin, M., 2012. Microeconomics, 9th ed., Cengage Learning, Stamford.

Brock, J.R., 1991, A Public Goods Experiment for the Classroom. Economic Inquiry, 29 (2), 395-401.

Chong, C-Y., and Cheng, D.C., 1975, Multistage Pricing Under Uncertain Demand. Annuals of Economic and Social Measurement, 4 (2), 311-23.

DeYoung, R., 1993, Market Experiments: The Laboratory versus the Classroom. The Journal of Economic Education, 24 (4), 335-51.

Dickie, M., 2006. Do Classroom Experiments Increase Learning in Introductory Microeconomics? The Journal of Economic Education, 37 (3), 267-88.

Dolan, R.J., and Abel, P. 1981. Experience Curves and Dynamic Demand Models: Implications for Optimal Pricing Strategies. Journal of Marketing, 45 (1), 52-62.

Doyle, W., and Carter, K. 1984. Academic tasks in classrooms. Curriculum Inquiry, 14, 129-149.

Durham, Y., T. McKinnon, and C. Schulman, 2007. Classroom Experiments: Not Just Fun and Games. Economic Inquiry, 45 (1), 162-78. 
FeIs, R., 1993. This is What I Do, and I Like It. The Journal of Economic Education, 24 (4), 365-70.

French, N.R., and S.C. Turner, 1989. The Introduction of Experimental Economics in the Agricultural Marketing Classroom. NACTA, 33, 33-36.

Holt, C.A., 1999. Teaching Economics with Classroom Experiments: A Symposium. Southern Economic Journal, 65 (3), 603-610.

Leuthold, J.E., 1987. A Public Goods Experiment for the Classroom. The Journal of Economic Education, 18 (1), 58-65.

Lynch, G.J., 1990. The Effect of Teacher Course Work on Student Learning: Evidence from the TEL. The Journal of Economic Education, 21 (3), 287-296.

Meyer, R.A., 1975. Monopoly Pricing and Capacity Choice Under Uncertainty. The American Economic Review, 65 (3), 326-37.

Nelson, R.G., and Jr.R.O. Beil, 1994. Pricing Strategy under Monopoly Conditions: An Experiment for the Classroom. Journal of Agricultural and Applied Economics, 26 (1), 287-98.

Nelson, R.G., and Jr.R.O. Beil, 1995. A Classroom Experiment on Oligopolies. Journal of Agricultural and Applied Economics, 27 (1), 263-75.

Nocke, V., and M. Peitz, 2003. Monopoly Pricing Under Demand Uncertainty: Final Sales Versus Introductory Offers. [pdf] Available at: http://papers.ssrn.com/sol3/papers.cfm?abstract_id=370681 [Accessed February 15, 2014].

Oxoby, R.J., 2001. A Monopoly Classroom Experiment. The Journal of Economic Education, 32 (2), 16068.

Parker, J. 1995. Using Laboratory Experiments to Teach Introductory Economics. [pdf] Available at: http://academic.reed.edu/economics/parker/ExpBook95.pdf [Accessed February 15, 2014].

Requate, T., and I. Waichman, 2011. A profit table or a profit calculator? A note on the design of Cournot oligopoly experiments. Experimental Economics, 14 (1), 36-46.

Rosenthal, R., 1976. Experimenter Effects in Behavioural Research, Irvington: New York.

Saunders, P., 1980. The Lasting Effects of Introductory Economic Courses. The Journal of Economic Education, 12 (1), 1-14. 
Spulber, D. 1991. Monopoly Pricing Strategies. [pdf] Available at: http://www.kellogg.northwestern.edu/research/math/papers/936.pdf [Accessed February 15, 2014].

Stigler, G.J., 1963. Elementary Economic Education. The American Economic Review, 53 (2), 653-59.

Sulock, J.M., 1990. The Free Rider and Voting Paradox Game. The Journal of Economic Education, 21 (1),65-69.

Walker, J., 1987. Experimental Economics in the Classroom. The Journal of Economic Education, 18 (5), $51-57$.

Zizzo, D., 2010. Experimenter demand effects in economic experiments. Experimental Economics, 13 (1), 75-98. 